\title{
Conceptual Architecture for the Continuity if Workflow in Activities on Multi-Devices: Case Study Co- Kitchen
}

Mirian Janeth Avalos-Viveros 1,*, Luis Gerardo Montané-Jiménez ${ }^{1}$, Gabriela Sánchez Morales², Carmen Mezura-Godoy ${ }^{1}$, Edgard Benítez-Guerrero ${ }^{1}$

${ }^{1}$ Facultad de Estadística e Informática, Universidad Veracruzana, 91020, Mexico

${ }^{2}$ Department of instruction and knowledge management, Universidad de las Américas Puebla, 72810, Mexico

\begin{tabular}{l} 
A R T I C L E I N F O \\
\hline Article history: \\
Received: 31 May, 2019 \\
Accepted: 02 August, 2019 \\
Online: 21 August, 2019
\end{tabular}

Keywords:

Continuity

Workflow

Multi-device

\begin{abstract}
A B S T R A C T
Nowadays, the realization and follow-up of a team activity takes place in different execution environments (e.g. mobile phone, PC) through the use of computer applications. This implies context changes that generate interruptions in the activity. To improve the continuity of an activity with the reduction of interruptions during the development of this activity, would help to finish a task in a shorter time. An example of interruption occurs when a user initiates an activity on a device and decides to continue working on it on a different device, thus facing additional steps that must be performed to obtain the updated information on the desired device. The interruptions can be found in several domains as in the previous example that refers to the work developed through multi-devices or collaborative systems (CS). In this article we present a proposal for a model that incorporates the continuity attribute in the CS development process, to support its users to carry out Collaborative Activities (CA) through different devices with the least possible number of interruptions, so that that way the user does not require additional steps that extend the time of the task and negatively affect the process of transferring his CA to another device.
\end{abstract}

\section{Introduction}

This article is an extension of a previous work, in which a Conceptual model to improve the continuity of the workflow of collaborative activities in multi-devices is presented [1]. Collaborative activities can be developed within the Collaborative Systems (CS). CS allow a team of people to work on a common task, through a user interface in a shared environment, virtually [2]. Currently, due to the increase in the capabilities of mobile devices, these are used to perform different activities, gradually replacing the need for the use of a personal computer. This allows to conceptualize that the users of a CS can interact from any of their devices. An example of this scenario is a group of people which for different reasons of time and space decide to use a tool that

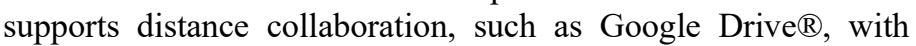
which it is possible to give continuity to an activity from a laptop, a tablet or a mobile phone.

The flow of continuity of an activity is limited due to the additional steps that are required to perform activities in multi-

\footnotetext{
* Mirian Janeth Avalos-Viveros, Email: zs17000719@estudiantes.uv.mx
}

devices $[3,4]$. These additional steps are considered interruptions, which are presented once the user wishes to continue performing an activity in a new device, such as: saving progress made in the source device, to later $\log$ in to the target device, open the application and position to the last state or download the advances in the new device; to name a few. It is important to mention the existence of tools that offer the user a flow of activity that involves fewer steps such as Apple AirPlay ${ }^{\circledR}$, which in conjunction with Apple TV® wirelessly transmits movies, music and photos from any IOS $\AA$ device; or Google Drive $\AA$ offering the creation of content and editing flow, documents, photos and videos, allowing users to access them from any device.

Due to the problem described above, in this work we propose a model that offers continuity to the workflow of CA with support to multiple devices, seeking to reduce the number of interruptions that the user faces each time he wishes to resume a task in a different device. That is, for any user, the process of transferring the last state of information from one device to another is transparent. 


\section{M.J. Avalos-Viveros et al. / Advances in Science, Technology and Engineering Systems Journal Vol. 4, No. 4, 478-484 (2019)}

The structure of this article is as follows: Section 2 addresses the aspects of Collaborative Systems, Collaborative Activities, Workflow and Continuity. Section 3 presents papers that support continuity in the workflow. Section 4 shows the challenges and opportunities identified from the analysis of the state of the art. Section 5 presents the proposal of a conceptual model that offers continuity in the CA workflow in multi-devices. Section 6 shows the proposal of a conceptual architecture for the construction of a CS under the concept of continuity. In section 7 a case study is presented to be implemented under the proposed model and architecture, as well as the design of the prototype. Finally, section 8 presents the conclusions and introduces future work.

\section{Collaborative activities and Workflow}

\subsection{Collaborative systems}

$\mathrm{CS}$ are computer systems that support collaborative work among groups of people who share common goals [2]. These CS are classified based on space, where collaborators can be found in the same place or in different geographical spaces; also, they are classified based on time, where people work at the same time (synchronous), or at different times (asynchronous) [5].

The CS offer functionalities for communication, coordination and collaboration, also known as the $3 \mathrm{C}^{\prime} \mathrm{s}$. The communication is through the sending and receiving of messages between team members, as well as the way in which these users observe what the rest of their team is doing. The coordination provides the way to organize the activities to be carried out. The collaboration considers functionalities necessary for users to achieve a collaborative activity $[6,7]$.

\subsection{Collaborative activity}

In [8] the activity theory (AT) is presented, representing it in a triangular figure with the elements that intervene in a collaborative activity and its relationship. The elements that make up the triangular system of activity correspond to: subjects, tools, community, division of labor, rules, objects and results; in [9] it is described as the relationship given by the link that exists between two elements of the system with another of the same. During the development of a CA, the people who are involved are immersed in a little-explored element so far: the workflow, by means of which one can know the interruptions that are generated during the life cycle of a task; for example, an interruption to the continuity of the workflow could occur when the user is writing a text on his cell phone and receives a phone call. At this moment, the flow is interrupted and the continuity suffers pauses due to the change of context.

\subsection{Workflow}

The workflow of an activity is a set of actions that need to be carried out to achieve a specific purpose. The [3] workflow considers two types of activities: individual activity flow and flow of sequenced activities. In the flow of individual activity, the user carries out only one activity, for example: watching a video, reading a book, editing a text, among others, making use of different devices, where each of them takes up the activity from the same point where the previous device left it. While in the stream of sequenced activities, the task flow is composed of different activities that must be performed by users to achieve the final goal; generally, each activity is carried out in a different device according to the needs of the activity, in different contexts of space and time [10]. The flow of activity suffers interruptions in its process due to changes in context, as previously mentioned; that is, there is no continuity in the process of completing a task.

\subsection{Continuity}

Continuity can be defined as the execution of steps without interruptions. The duration of an activity is an important factor that allows to determine the continuity within a task that is being carried out through a device. For that purpose, it [3] shows three ways in which the flow of continuity is carried out in accordance with the duration of the activity: multiple sessions, context changes and their tasks. With multiple sessions, when an activity is extensive, the user manages to complete it in multiple steps and different devices, depending on the context. While, in context changes of an activity, the user ends session and later takes it back, perhaps in a new device depending on the context where the user is. However, in the case of subtasks, when an activity is relatively extensive, it can be divided into subtasks; which can be different from each other and require a different place of context (time, location, among others.), therefore they can be made in different devices. Figure 1 shows the example of the user John who is in different context changes during the performance of a particular activity. He begins his work at his school using a desktop computer but changes the context to work using his laptop; this generates interruptions (represented by spikes, see Figure 1) that the user faces when he decides to transfer the information to a new device. Later, the user John decides to stop using the desktop computer to continue working from his tablet or cell phone, because he needs to be in motion (in this case he is experiencing interruptions to make possible the transfer of workflow). Finally, when he returns to his work area (school kitchen), he projects the content of the activity on a screen.

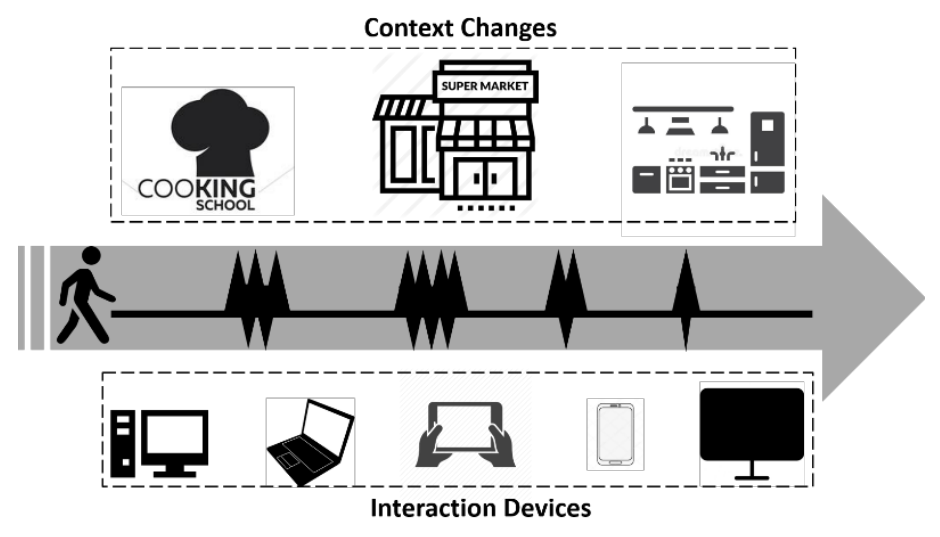

Figure 1: Continuity of a task with changes of context and devices.

\section{Works on the continuity in the workflow}

Currently, most people have multiple devices and interact with each other to perform their daily tasks [4, 10, 11], this because mobile devices (cell phones or tablets) have capabilities similar to those of a desktop computer or laptop, as people seek to try to keep their work at their disposal at all times. But this has brought unattractive events for users, for example: [12] discovered that when there was no storage in the cloud, people e-mailed the URLs of the websites they visited, to access them from a different device; in [11], a study finds that there are systems with an unintuitive design so that users have continuity in the interaction with multiple devices. In scenarios like this, where the user wants to work with 


\section{M.J. Avalos-Viveros et al. / Advances in Science, Technology and Engineering Systems Journal Vol. 4, No. 4, 478-484 (2019)}

the devices, the transfer of the task between each device becomes a negative charge.

As a consequence of the lack of continuity in the process of carrying out the activity, there is a disconnection between the actions required of the user when he is using multiple devices [7].

As time passes, proposals have been sought to solve the lack of continuity with the aim of providing the user with the way to transfer information from one device to another without the intervention of unfavorable solutions such as: email, desktop software remote, USB drives, among others. Koren and others, in [13] propose an architecture for the mobility of the session of applications between different mobile devices, within the contributions include support for the discovery of nearby devices and the transfer of sessions with support for interactions based on the exchange of messages and files. However, they present problems in the transfer of the status of the activity.

Cabarcos and others, in [14] propose the design of an architecture for single session initiation in multi-devices (SuSSo) that includes the definition of storage formats of flow of operation session for the transfer of information in an abstract level, so that it can be easily implemented in any electronic device and guarantee interoperability of the cloud service in all devices; in this way sessions initiated from a device transfer their content to a second device without any problem.

Salminen and others, in [15], propose the implementation and evaluation of a middleware to migrate the user interface. The middleware is responsible for having control in the handling of events of the user interface and, in this way, the aforementioned component is transparent for the application. According to the tests carried out by the authors, the studies show that the preference for doing a task in a mobile device depends on the degree of familiarity that the user has with the keyboard of his cell phone, and they consider not having the need to incorporate a new method in order to finish their task before.

Cheng in [16]proposes a middleware capable of handling communication through different devices. The virtual browser facilitates operations between devices according to a predefined file. This research divides a DOM tree into multiple sub_DOM trees, to dynamically manage subviews on multiple devices and link them into a single virtual device. The author presents problems in the development of his proposal, for example: the difficulty to share events and the synchronization of elements and statuses.

Ghiani and others, in [17] present a process of migration for the permanence of status of the tasks that the user is doing in the device called source to the target device, that is, to which he wants to move the user interface to continue his interaction. The authors seek to provide: i) flexible support in several aspects taking into account the variety of possible devices that users may want to use, and ii) an accessible solution for the migration of any application developed with standard Web language, without using any specific complement. According to the tests carried out in this work, they obtained two variants as a result of user evaluations: ease of use and utility.

Pyla and others, in [18] designed a continuous user interface prototype that guarantees a seamless migration of tasks for users who try to perform a specification of requirements and collect tasks, using a tablet and a desktop computer. This system provides support for automatic migration of the task context (eg, applications that were in use) between two devices. In an evaluation carried out, the participants informed that the proposal helped to mitigate the effects associated with the disconnections of tasks, also informed that the automatic availability of the necessary data in the computers and modules contributed directly to a higher perceived reliability and lower error probability.

Currently, there are proprietary applications that offer continuity during the flow of activity, these are available for public use where some have cost and others are freely available, such as: Google Drive $\AA$, Netflix ${ }^{\circledR}$, Office package $\AA$, among others. In

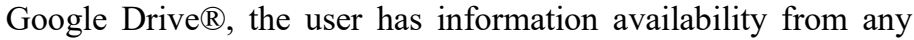
device, as long as the device is linked to the same email account; the changes that are made are automatically saved by the tool. In the case of Netflix ${ }^{\circledR}$, the user can access the exact minute in which he was watching a movie or series in his last session. In desktop systems such as the Office ${ }^{\circledR}$ parcel, if a document that has already been edited is opened, it asks the user if he wishes to continue working from the place where he was previously doing it. In [18] and [19], studies are presented to users where they interact with at least two devices to perform a task. Among the results obtained, an aspect that stands out from the others is the need to have a continuous interface design, for the process of information transfer with fewer steps towards a new device. Additionally, in [19], the authors consider that this aspect could improve the user's experience when interacting with multi-devices in the development of tasks.

Table 1: Summary of related works

\begin{tabular}{|c|l|l|}
\hline Work & Collaborative & \multicolumn{1}{|c|}{ Problems } \\
\hline $\begin{array}{c}\text { Koren el at. } \\
(2013)\end{array}$ & Yes & $\begin{array}{l}\text { When the transfer of activity states is } \\
\text { made to a new device, there is loss of } \\
\text { information. }\end{array}$ \\
\hline $\begin{array}{c}\text { Cabarcos } \\
(2012)\end{array}$ & No & $\begin{array}{l}\text { The entire state of the task is not } \\
\text { preserved. }\end{array}$ \\
\hline $\begin{array}{c}\text { Cheng (2012) } \\
\text { Ghiani et al. } \\
(2012)\end{array}$ & No & $\begin{array}{l}\text { Conflict when several devices share } \\
\text { information. }\end{array}$ \\
\hline $\begin{array}{c}\text { Salmien et al. } \\
(2007)\end{array}$ & No & $\begin{array}{l}\text { Registration to the platform is } \\
\text { required to obtain continuity in the } \\
\text { devices. }\end{array}$ \\
\hline $\begin{array}{c}\text { Pyla et al. } \\
(2009)\end{array}$ & No & $\begin{array}{l}\text { Additional steps that users seek to } \\
\text { avoid. }\end{array}$ \\
\hline
\end{tabular}

In our review of the literature, limited efforts were found that seek to provide continuity in the workflow through multi-devices. Table I summarizes the problems of the papers presented in this section; it is also indicated that only two out of the six works have a collaborative approach as proposed in this research work.

\section{Challenges and opportunities to support the continuity of the workflow.}

In an exploratory way, we conducted a preliminary study with two teams of five members, each of which held a Collaborative 
Activity that included two tasks; the Google Drive ${ }^{\circledR}$ tool was used to perform the tasks. In the first task, they used their computer; once finished this, they had to change device. The second task was developed using their cell phone. After performing the activity by teams, the users were questioned about their experience when doing the activity in multi-devices.

As a result of the exploratory study, we observed that the majority of users usually do tasks through their different devices, but they express displeasure when they need to execute a series of steps to change the device, such as opening the application in the cell phone or downloading the advance in the new device; reason why some users requested to continue the activity from their computer, to avoid extending the time of completion of the task due to interruptions.

Therefore, within the identified challenges and opportunities, is to build a mechanism for the development of Collaborative Systems that transfers information between multi-devices with the least number of interruptions, achieving so that users can work on their tasks not only from their office, school or area where they normally do it, but from any context in which they find themselves and wish to continue working through the device that best adapts to the context. In this way, the user would be provided with a way to carry out Collaborative Activities from any of their devices whenever they wish, according to their needs and interaction preferences, and without being limited to working only in specific spaces.

\section{Conceptual model for the continuity of the workflow}

As a consequence of the analysis of the works related in this research, this article proposes the Model 4C's, as a frame of reference to provide the Collaborative Systems developers with the continuity element.

With the Model of the 4C's, the number of interruptions can be reduced through continuity support, to minimize additional steps when the user resumes work on a new device. Another contribution of the Model of the 4C's, is to allow users to carry out collaborative activities in multi-devices without affecting the workflow of the CAs by the operating system or the user's context change.

The Model of the 4C's is an instance of the Model 3C's, which arises from the models: 3C's [2] , [19], Mars [20] and CAMCOS [21], taking components such as: communication, cooperation, coordination, workspaces, actors, interactions; which in turn are linked to the continuity element proposed in this work. The 4C's model is shown in Figure 2.

In a Collaborative Activity, groups of actors (users) participate in a group work space to carry out joint activities; These actors also have an individual work space, a space in which each user carries out their activities independently. Within both spaces, users perform different interactions that represent actions to complete a particular activity, which are executed within the three properties of the CS: communication, coordination and cooperation; but, in addition, continuity is required to offer the user the possibility of interacting through different devices during the performance of a task.

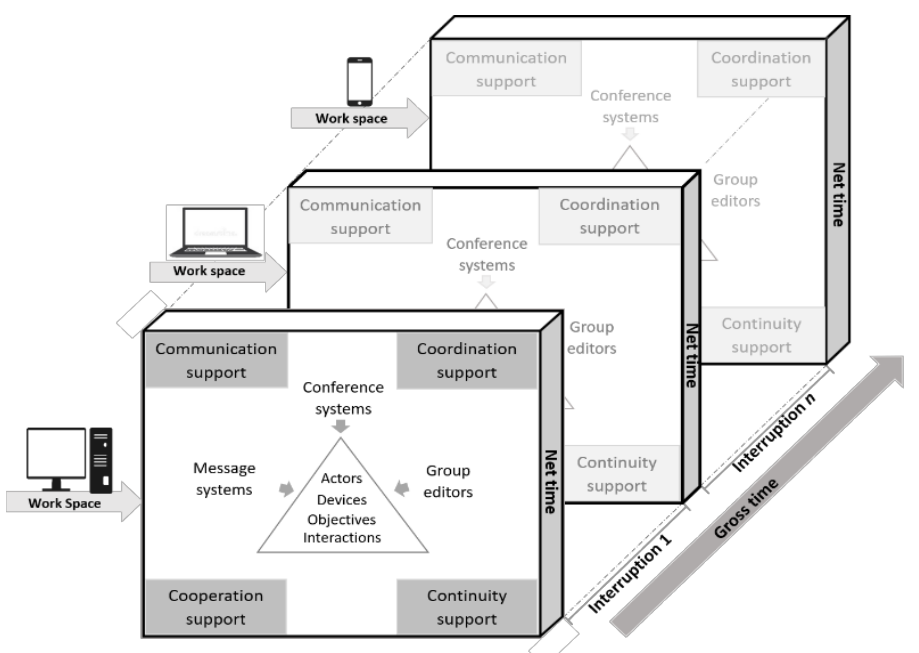

For this reason, it is necessary to include in the 3C's model of [4] the continuity element, which provides the user with permanence of the last status of the task when a context change is presented, that is, when the user for external reasons or preference of interaction is in the need of leaving the device with which he initiated the CA and requires to retake it in a different device. In order to provide continuity to the CA workflow through multidevices, the 4C's model considers 8 elements: 1) Family of actors, 2) Actors, 3) Roles, 4) Objects, 5) Tasks, 6) Interactions, 7) Artifacts and 8) Work spaces; which are described in Table II. These elements are interrelated to propitiate an environment that minimizes interruptions in the sense that the statuses of each of them can be transferred to another device.

Table 2: Elements of the $4 \mathrm{C}$ 's model for collaborative applications.

\begin{tabular}{|c|l|}
\hline Elements & \multicolumn{1}{|c|}{ Description } \\
\hline Family of actors & $\begin{array}{l}\text { Set of names of actors where each actor has a different } \\
\text { role. }\end{array}$ \\
\hline Actors & $\begin{array}{l}\text { People or software that carry out CA, through the } \\
\text { interaction of different artifacts }\end{array}$ \\
\hline Roles & $\begin{array}{l}\text { Role that each user plays within the realization of an } \\
\text { AC. }\end{array}$ \\
\hline Objects & $\begin{array}{l}\text { Everything that the actor can manipulate through } \\
\text { interactions to achieve goals. }\end{array}$ \\
\hline Actions & $\begin{array}{l}\text { Actions that the user carries out to fulfill the } \\
\text { collaborative activity. }\end{array}$ \\
\hline Interactions & $\begin{array}{l}\text { Realization of an action by a user through different } \\
\text { artifacts within the system. }\end{array}$ \\
\hline Mechanism & $\begin{array}{l}\text { Hardware that the user uses to carry out his AC, within } \\
\text { the SC, such as cell phone, tablet, laptop, desktop } \\
\text { computer, among others. }\end{array}$ \\
\hline Workspaces & $\begin{array}{l}\text { Place where actors perform their actions in a group or } \\
\text { individual way through an mechanism. }\end{array}$ \\
\hline
\end{tabular}

\section{Conceptual architecture}

Based on the 4C's conceptual model, we designed a conceptual architecture that supports the continuity of the CA workflow, through which the user can work in a collaborative activity from different mobile devices with a reduced number of interruptions in the process of information transfer and status of the task. The proposed architecture is shown in Fig. 3. 


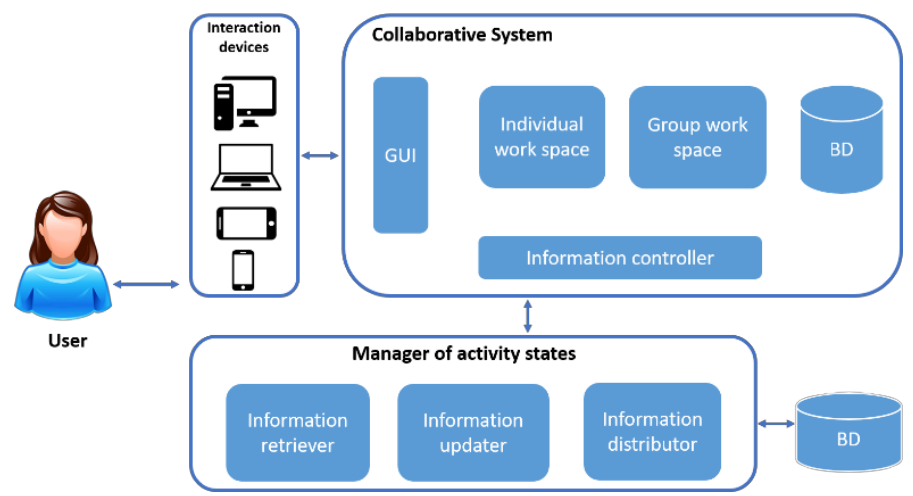

Figure 3: Conceptual architecture of the 4C's model

The continuity support starts once the user selects the device to start the CA. The interaction device is the means of communication between the application and the user. It is responsible for sending requests to the system in order to obtain updated information, and the system receives these requests through the activity's status manager.

Within the activity's status manager, three components are considered: an information retriever, an information updater and an information distributor. The information retriever obtains the last modifications of the users, in addition to the last workspace where they stopped.

The information updater is responsible for unifying the information of the individual and group workspace of the users and generates a new version of the progress of the team's work. When the user wants to resume the activity in a new device, the information distributor obtains the latest version of the work's progress and shows it to the user from the workspace in which he/she is working, supporting in this way the continuity of the workflow of the collaborative activity in multi-devices.

\section{Case study}

Based on the elements of the 4C's model and the conceptual architecture proposed above, a case study is being addressed through a scenario where, during the process of developing an CA, it is required to transfer the information to different mobile devices, in order to test whether the elements identified in the conceptual architecture are sufficient to provide the user with a continuous workflow, in the performance of collaborative activities in multi-devices.

The case study was modeled so that a team of actors worked on different activities for a common goal (to prepare a dish and generate a recipe). There are three types of actors: the administrator (teacher of the cooking school), the team representative and the members of the work team. Each actor plays a role within the collaborative activity; the administrator is the evaluator of the final product that each team elaborates, the team representative is the organizer of activities within the team and the member of the team is the buyer of ingredients. The actors interact with different artifacts during the collaborative work process such as: a desktop computer or a laptop to send the list of ingredients to the work team, as well as to make the recipe for the final product; a cell phone to perform tasks that require user mobility such as going to a supermarket to buy the ingredients of the dish; a tablet where users can count on a broader work space compared to the telephone, but also with mobility in the different workspaces where the actors must move to meet the objective of the activity.

The design of the Co-Kitchen system was made using the user-centered design methodology, an approach that allows iterations with the design throughout the life cycle of the product and in this way to redesign the system in order to meet the expectations and needs of end users [22]. Within the work framework for the design of human-centered interactive systems [23], the design process starts from the understanding of the context of use to specify the requirements of users, make a proposal of design solution and finally evaluate the design.

Phase one of the design process has been specified at the beginning of this section, where the modeled study case is detailed. Once analyzed and understood the context of use, we identified the requirements that the actors have in accordance with what they do within the system; in this way we knew the functionalities that the system should provide. In Table III, the functionalities of the system are described.

Table 3: Functions of the prototype Team Cooking

\begin{tabular}{|l|l|}
\hline Function & \multicolumn{1}{|c|}{ Description } \\
\hline $\begin{array}{l}\text { Create team } \\
\text { Create list of } \\
\text { ingredients }\end{array}$ & $\begin{array}{l}\text { The administrator can create a work team. } \\
\text { that the team must use to prepare a dish. }\end{array}$ \\
\hline Assign tasks & $\begin{array}{l}\text { The team representative is responsible for assigning } \\
\text { tasks to each member of the team. Tasks such as } \\
\text { buying ingredients, looking for kitchen utensils, } \\
\text { lighting the oven, among others. }\end{array}$ \\
\hline Create recipe & $\begin{array}{l}\text { All the team at the end of the proposed dish, should } \\
\text { generate a recipe for cooking it; for this each one } \\
\text { must describe within the kitchen format the } \\
\text { procedure for the realization of it, resulting in the } \\
\text { recipe of the dish. }\end{array}$ \\
\hline
\end{tabular}

Once the requirements and functionalities that the system should provide the user in order to carry out his tasks were identified, the next step was to create the proposed design solution, which is shown and described below in Figures 4, 5, 6 and 7.

For the design of the proposal we use standard components such as: buttons, menus, text fields, etc., as well as: pointers, chat, and lists of connected users, according to [24] [25], who propose to simplify the development of groupware interfaces and to reduce the time of information search by grouping related elements in such a way that it is easy for the user to identify in which section is the element that he requires in order to perform a task.

In Figure 4, the start screen that the team representative actor displays when logging into the system is displayed. On the left side are the actions that can be executed within the system, in the center part of the screen you can see the work area and on the right 
side there is the collaboration area where, through a list of connected users, the actor is kept informed of the presence of users who are collaborating during the realization of the CA and, at the top of that same side, we can also see the presence of each member, as well as the progress that each one of them has.

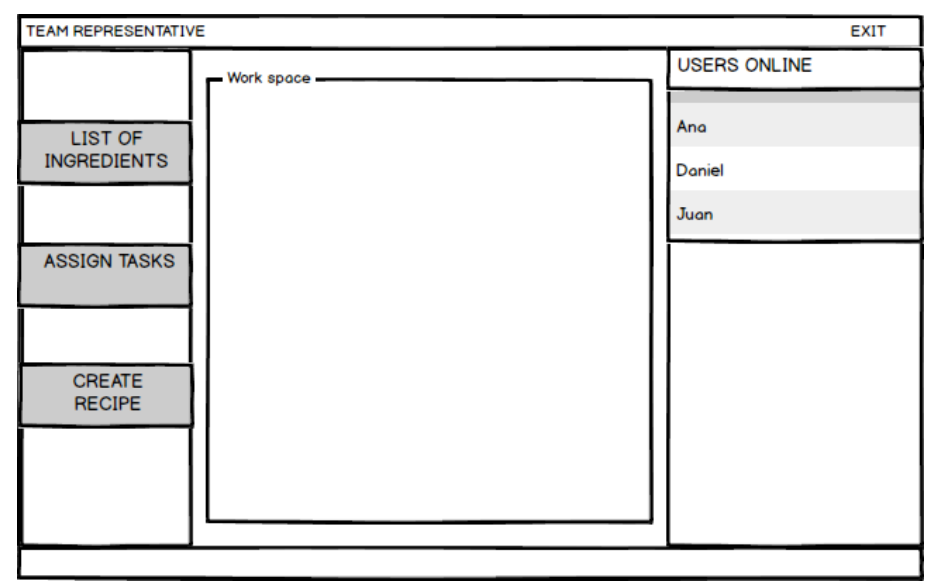

Figure 4: Team representative window.

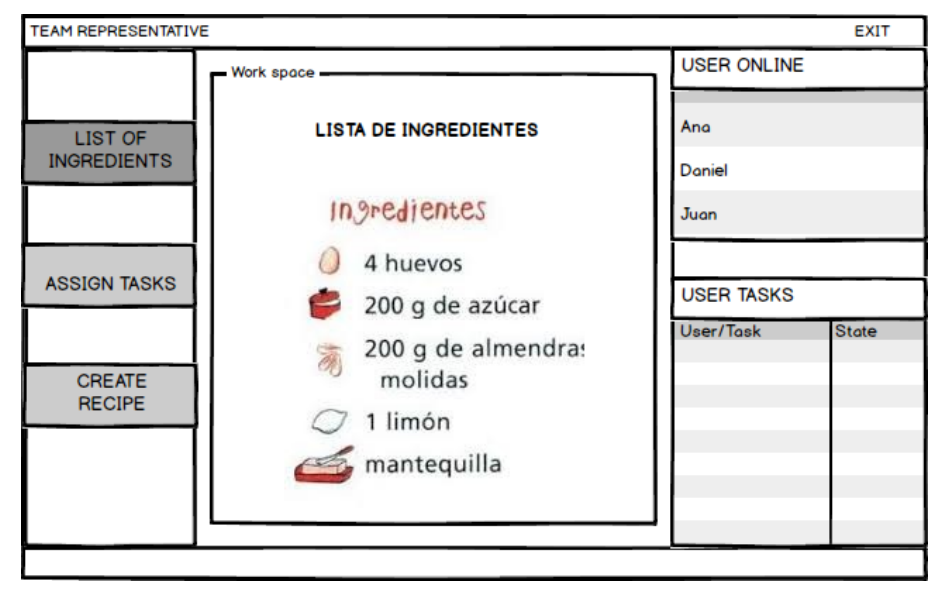

Figure 5: Window to visualize list of ingredients.

In Figures 5, 6 and 7, what happens when the user clicks on one of the buttons on the left side is shown. When selecting "List of ingredients" (see Figure 5), in the work area the list of ingredients that was sent by the teacher of the cooking class is loaded. In case of selecting the option "Assign tasks" (see Figure 6), within the work area the team representative can enter the tasks assigned to each member of their team, which once assigned arrive as notification to the members to begin to work on them.

Finally, for the option to create a recipe (see Figure 7) within the work area, the actor works together with the rest of the team members in making the previously prepared recipe. Since it is a shared work area, each user has access to specific areas of the recipe according to the tasks previously assigned, which can be reported and described in the recipe.

The design of the solution proposal corresponds to a Web version loaded from a laptop or a tablet, but in the case of using a mobile device such as a cell phone, the design of the interface must be redesigned to fit a smaller screen, so that the work area is www.astesj.com not affected and so the actor can work through it without complications.

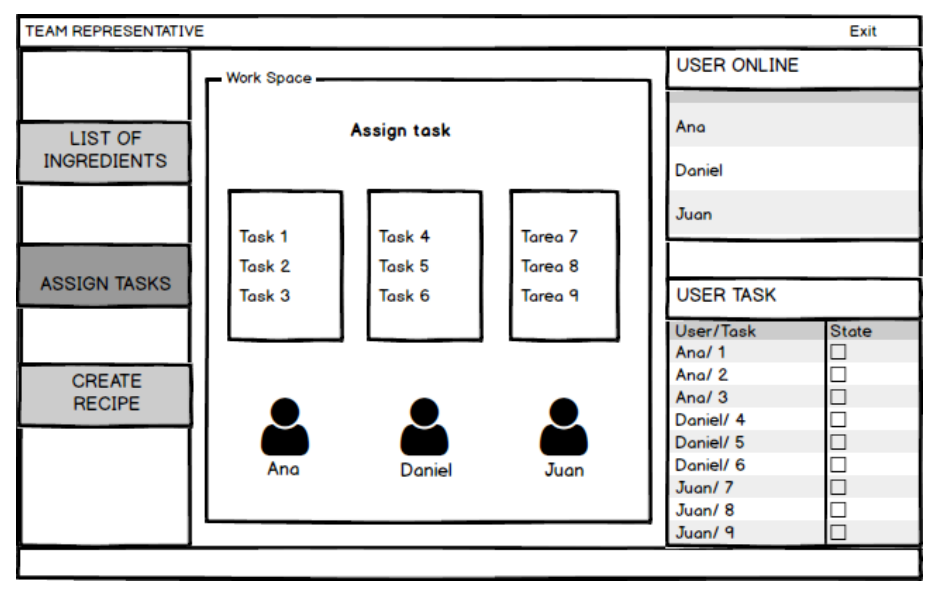

Figure 6: Window to assign tasks

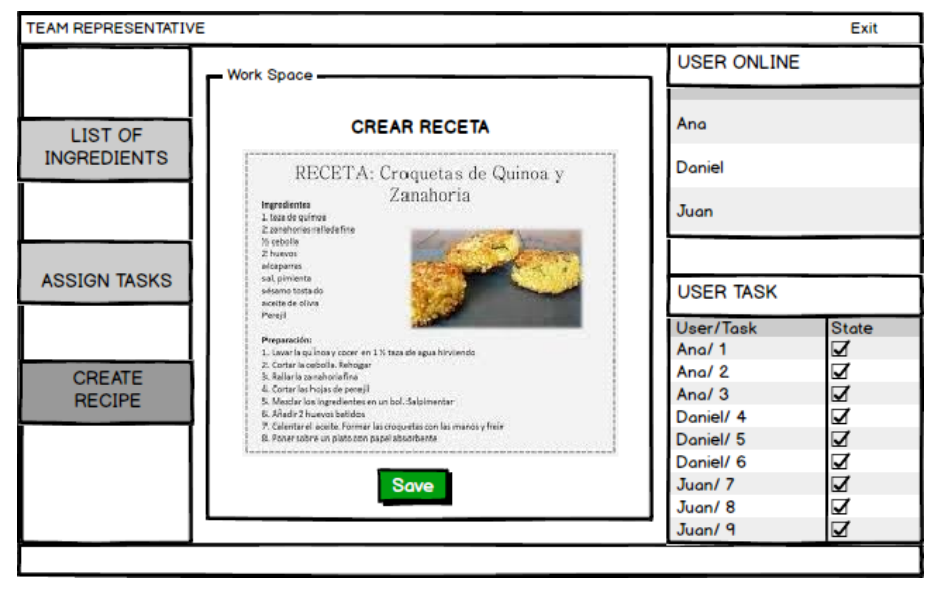

Figure 7: Window to create recipe.

\section{Conclusions and future work}

The advance of technology generates systems for collaboration between groups of people that interact with each other through the computer. Nowadays, it is possible to carry out an activity from different mobile devices such as: a cell phone, a tablet or a laptop, providing the user mobility to perform their activities. However, there is a gap in the conservation of the task status when moving to a new device. Therefore, this problem needs to be addressed in order to offer users systems that provide continuity to their workflow by requiring changes in the context of use during the performance of a task. That is why in this article we propose the model of the 4C's and the conceptual architecture to support users to carry out a collaborative activity in multiple devices in a shorter time. This proposal includes the continuity element of the model $3 \mathrm{C}^{\prime} \mathrm{s}$ of [2], and the manager of states in the conceptual architecture, seeking to minimize the number of interruptions during the transfer of information from the collaborative activity through different mobile devices

As future work, we plan to continue with phase four of the framework for the design of interactive human-centered systems [23], corresponding to the evaluation of the design proposal 
presented in this article, to subsequently work on a redesign under the observations and suggestions obtained from its evaluators.

Once the iterations of the design and evaluation process of the system design proposal have been finalized, we will give the appropriate follow-up to the construction of the Co-Kitchen system, to subsequently test the system and test whether our proposal effectively improves the continuity of the workflow of a collaborative activity when it is carried out through multi-devices, reducing the time in the interruptions that the user experiences when transferring and resuming the activity in a new device.

\section{References}

[1] L. G. M. -J. G. S. M. C. M.-G. a. E. B.-G. M. J. Avalos-Viveros, "“"Conceptual Model to Improve Continuity of the Workflow of Collaborative Activities in Multi-Devices" International Conference on Information Systems and Computer Science (INCISCOS). IEEE, pp. 233 $238,2018$.

[2] C. A. ELLIS, S. J. GIBBS y G. REIN, "Groupware: some issues and experiences" Communications of the ACM, vol. 34, n 1, pp. 39-58, 1991.

[3] M. Levin, Designing multi-device experiences : an ecosystem approach to creating user experiences across devices, O'Reilly Media, 2014.

[4] K. MAJRASHI, M. HAMILTON y A. UITDENBOGERD, "Evaluating Cross-Device Transitioning Experience in Seated and Moving Contexts" de Proceedings of the 22nd Pacific Asia Conference on Information Systems (PACIS 2018)(Yokohama, Japan2018), AISEL, Yokohama, Japan, 2018.

[5] G. GERONIMO, V. CANSECO y H. DE LEÓN, "Breve Introducción a los Sistemas Colaborativos: Groupware \& Workflow" Temas-Universidad Tecnológica de la Mixteca, pp. 49-54, 2002.

[6] L. N. Yann Laurillau, "Clover architecture for groupware" In Proc. Conference on Computer supported cooperative work, ACM, pp. 236-245, 2002.

[7] C. G. a. S. G. D. Pinelle, "Task analysis for groupware usability evaluation: Modeling shared-workspace tasks with the mechanics of collaboration" ACM Transactions on Computer-Human Interaction (TOCHI), vol. 10, n 4, pp. 281-311, 2003.

[8] Y. Engeström, "Expansive learning at work: Toward an activity theoretical reconceptualization" Journal of education and work, vol. 14, n 1, pp. 133156,2001

[9] L. G. M. Jiménez, Presencia social en sistemas groupware, Tesis doctoral, Facultad de Estadística e Informática, Universidad Veracruzana, Xalapa, México, 2016.

[10] D. R. J. K. M. B. S. E. V. R. a. B. M. L. J. Paay, "Investigating CroosDevice Interaction between a Handheld Device and a Large Display" In Proc. of the 2017 CHI Conference on Human Factors in Computing Systems. ACM, pp. 6608-6619, 2017.

[11] J. K. a. M. B. S. D. Raptis, "Continuity in multi-device interaction: an online study" In proc. of the 9th Nordic Conference on Human-Computer Interaction. ACM, p. 29, 2016.

[12] H. B. a. S. D. W. Jones, "Keeping found things found on the web" Tenth international conference on Information and knowledge management. ACM, pp. 119-126, 2001.

[13] D. S. a. T. S. I. Koren, "Session mobility for collaborative pervasive apps using XMPP" Pervasive Computing and Communications Workshops (PERCOM Workshop), IEEE Internacional Conference on. IEEE, pp. 169174, 2013.

[14] F. A. M. R. S. G. A. M. L. a. D. D.-S. P. A. Cabarcos, "Susso: seamless and ubiquitous single sign-on for cloud service continuity across devices" IEEE Transactions on Consumer Electronics, vol. 58, n 4, pp. 1425-1433, 2012.

[15] S. H. a. J. R. T. Salminen, "Middleware based user interface migration: implementation and evaluation" In Proc. of the 4th international conference on mobile technology, applications, and systems and the 1st international symposium on Computer human interaction in bobile technology, ACM, pp. 358-363, 2007.
[16] B. Cheng, "Virtual browser for enabling multi-device web applications" In Proc. of the Workshop on Multi-device App Middleware. ACM, pp. 3-7, 2012 .

[17] F. P. a. C. S. G. Ghiani, "Push and pull of web user interfaces in multidevice environments" International Working Conference on Advanced Visual Interfaces. ACM, pp. 10-17, 2012.

[18] P. S. T. M. H. J. \&. P.-Q. M. A. Pyla, "Continuous user interfaces for seamless task migration" International Conference on Human-Computer Interaction, Springer, pp. 77-58, 2009.

[19] E. I. B. M. D. C. M. a. E. M. L. G. Montané, "Studying Social Interactions in Groupware Systems" IEEE Latin America Transactions, vol. 13, n 10, pp. 3488-3497, 2015.

[20] M. R. a. S. T. C. Mezura-Godoy, "Mars: Modelling arenas to regulate collaborative spaces" In International Conference on Collaboration and Technology, Springe, pp. 10-25, 2003.

[21] C. M.-G. a. L. G. M.-J. E. Benítez-Guerrero, "Context-aware mobile collaborative systems: Conceptual modeling and case study" Sensors, vol. 12, n 10, pp. 13491-13507, 2012.

[22] J. R. a. D. Chisnell, Handbook of usability testing : how to plan, design, and conduct effective tests, Indianapolis: Wiley Publishing, Inc., 2008.

[23] ISO, E. N. 9241-210: Ergonomics of human-system interaction. Humancentred design for interactive systems, 2010.

[24] V. M. R. M. L. L. M. D. G. J. L. G. J. A. N. M. .. \&. H. M. V. Penichet, "Una aproximación al proceso de diseño e implementación de interfaces de usuario para aplicaciones groupware" IX Congreso Internacional Interacción, pp. 19-28, 2008.

[25] C. Stephen, "A cognitive approach to the design of information graphics" CARNEGIE-MELLON UNIV PITTSBURGH PA DEPT OF PSYCHOLOGY, pp. AIP-143, 1991. 